\title{
Height Measurement System Based on Edge Detection Technique and Analysis of Digital Image Processing
}

\author{
Ida udlhiya ${ }^{1}$ Eko Supriyanto ${ }^{2}$, and Eni Dwi Wardihani ${ }^{3}$ \\ 1 Telecommunication Engineering Department, Politeknik Negeri Semarang, Indonesia \\ 2 Telecommunication Engineering Department, Politeknik Negeri Semarang, Indonesia \\ 3 Telecommunication Engineering Department, Politeknik Negeri Semarang, Indonesia
}

\begin{abstract}
Height measurement is important in the field of health, athletics, and others. During this process the measurement height is done manually by using the tools in the form of tape measure or ruler. This takes quite a long time. With the weaknesses of such height measurements, then on this research designed a height measurement system based on Digital Image Processing Techniques. The parameters used for this research is the distance of the camera, the height of the camera, the camera angle, the color of the shirt, and the position of the object. Testing is done by performing processing and digital image analysis. By using these techniques, it only takes 35 seconds to process measurement and results. In addition to the test results can be stored in the system database, making it easier for data archiving. Of the overall testing with parameters of the camera distance, the height of the camera, the camera angle, the color of the shirt, and the position of the object, resulting in a measurement of the height of a more objective and accurate with the level of accuracy of $99.5 \%$.
\end{abstract}

Index Terms— Digital Image Processing, Digital Image, Image Conversion, Image Analysis.

\section{Introduction}

Many of the problems that require image as input or the input of the system due to the limitations of the human being in terms of processing speed, efficiency, and other factors. One of the systems that need the image as input is on the process of measuring the height of the people. Height measurement is important in the field of health, athletics, and others. Height measurement to date is still often done manually[1]. This process takes relatively long ranges from 2 minutes to the measurement and recording of results.

Image processing techniques are the most commonly used is the conversion of images[2-6]. One of the techniques used to measure height with the RGB image conversion process image to HSV[7-8], then calculate the distance the minimum up to HSV until HSV maximum, process of thresholding erosion and dilation, after which the process of smoothing, and look for the point of the contour and point coordinates that will be calculated into the results of the measurements of height. The use of digital cameras on mobile devices can be utilized as a tool height measurement with triangles. For the process of shooting back and forth transfer processes performed on the camera to determine the angles and then count high with special beam method on the lens[9].

One of the methods by using digital cameras is quite effective for calculating space $3 \mathrm{D}$ distances. With the methods of measurement in use is the study of the distance of the camera and shotting distance horizontally or vertically on the results of capture[10]. With flaws and weaknesses in the height measurement system, so this research will be made height measurement system with image processing technique that is more simple.

The method used is the conversion of RGB image into a grayscale image, thresholding process to generate the value of the pixels will be counted into the results of the measured height[11-14]. The information presented also includes personal data (ID, name, age, address) as well as the results of the photos are taken away by the camera. With the whole process only takes a range from 35 seconds to process measurement and recording of results. Not only the efficiency of the time, but the results of the data can also be printed and stored properly in the database. It is certainly more efficient compared with the measurements and logging manually.

In this research, input from the system is full body photos are taken away from the camera and processed using digital image processing used to measure the height. The process consists of a RGB image, conversion to binary image, thresholding process and the analysis of the results of the calculation of the height. The process consists of a RGB image, conversion to binary image, thresholding process, and the analysis of the results of the calculation of the height. The parameters used in this research is the distance of the camera, the height of the camera, and camera angles.

This paper is organized as follow. Section II show the digital image processing technique and the concepts of formulation modelling to be used. Section III describes the proposed method and experimental setup. Section IV show result and discussion the accuracy of height measurenment and section $\mathrm{V}$ shows conclusions and future research. 


\section{Research Method}

The initial process that much done in image processing is changing the image grayscale image into RGB colored, this is done to simplify the image. RGB image can be converted into gray image with the operation point. In general the intensity is defined as the mean value of the three elements of color that is Red Green Blue (RGB). So that the value of grayscale which represents the intensity can be calculated[15].

$$
K_{0}=\frac{R_{i}+G_{i}+B_{l}}{3}
$$

The Equation ${ }^{3}(1)$ will get the conversion operations image as in Figure 1 . The process of conversion of RGB to 1 layer 3 layer grayscale image will produce a grayscale. In this image no there is no more color, there is only gray degree.

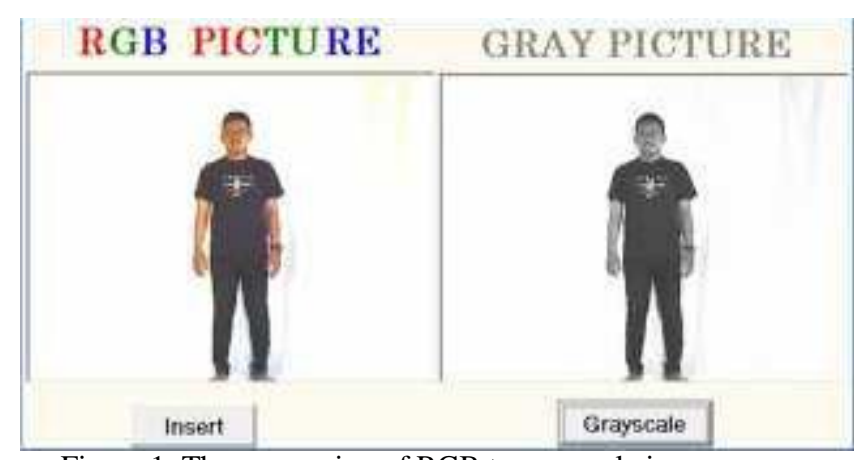

Figure 1 . The conversion of RGB to grayscale image.

To retrieve information from the pixels in the images, each component on character recognition system designed to reduce the amount of data. The first step is image preprocessing that aims to change the intensity of the pixels of the image so that it is easy to use in further proceedings. The stages are done in image preprocessing is the conversion of RGB to grayscale image black and white (binary image).

On a binary image format, every pixel has only two values so that only requires 1 bit memory for storing information. Therefore, this image processing program, image processing results remain in the binary format of the grayscale so that every byte of memory only stores information one point, thus processing is so much easier to do. Although the image format is grayscale, but only 2 values are used, namely 0 and 255[16]. This is done to manipulate binary (black-and-white) image. Can be seen in Figure 2.

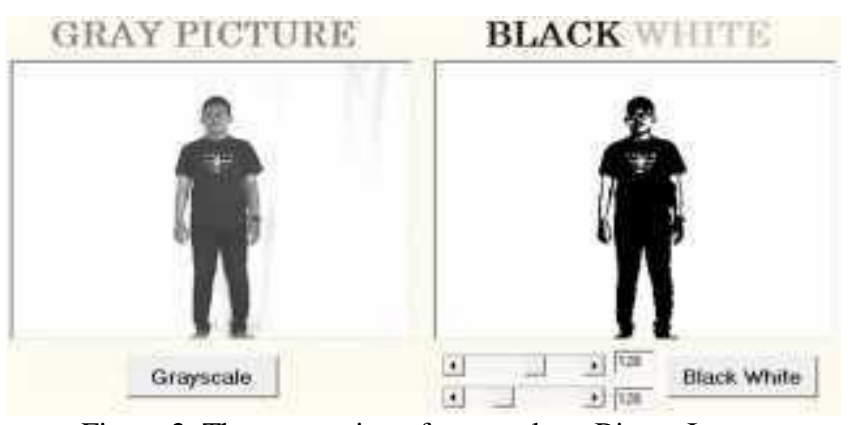

Figure 2. The conversion of grayscale to Binary Image

In the process of converting binary image, the process perambangan image (thresholding) was also conducted, by setting the upper and lower threshold value, then the result obtained will be a binary image that is perfect and intact. So the process of detecting edges can be calculated which will generate the number of pixels that will be converted to centimeter.

A digital image with a size of $320 \times 240$ pixels is a matrix with size of $240 \times 320.240$ indicates the number of rows and number of columns is 320 . The digital image is intended in the overall final project was "still image"[17]. Then, collect data in the form of images that are then analyzed digitally with the use of computers.

The result of the system will be analyzed by the process of pattern recognition or edge detection to make a decision or a number of pixels that form data is read from the scanning process ardethes results bfathebelpixels can be expressed as the height das (b)een measured through digital image processing. The height calculation using the Equation $(2)=. \times$

$$
l x=\frac{P X}{P r} \times l r
$$

That the $1 \mathrm{x}$ was the result of height measured, Px is the result of a reduction of the maximum and the minimum pixels pixels, $\operatorname{Pr}$ is correlation pixels that is 240 pixels, and lr is high correlation or high maximum that is $200 \mathrm{~cm}$.

Research on the design of digital image processing software systems and creation of database systems by using Borland Delphi 7.0 application. To process a high measurement system can be seen in the diagram of Figure 3.

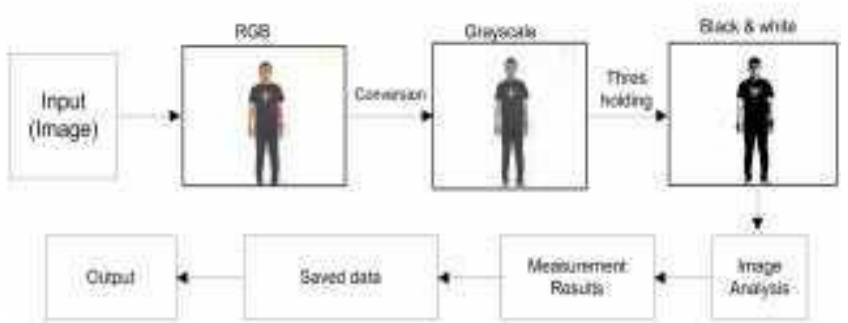

Figure 3. Diagram of the process-based height measuring system processing of digital image

The first is the process of taking pictures of the camera and the image is RGB image results. The RGB image is then converted to a grayscale image. After convert to grayscale image, the image will be converted into a binary image (black and white). In this process, the value of the threshold will be set to generate an image that the contrast 
between the color of the background that is white and black objects.

Black pixels at the top will be the minimum pixels and pixel black bottom became pixels maximum. The results of calculation of pixels are converted to unit centimeters stating the results of the measured height and stored in a database that will be shown in the output of the program.

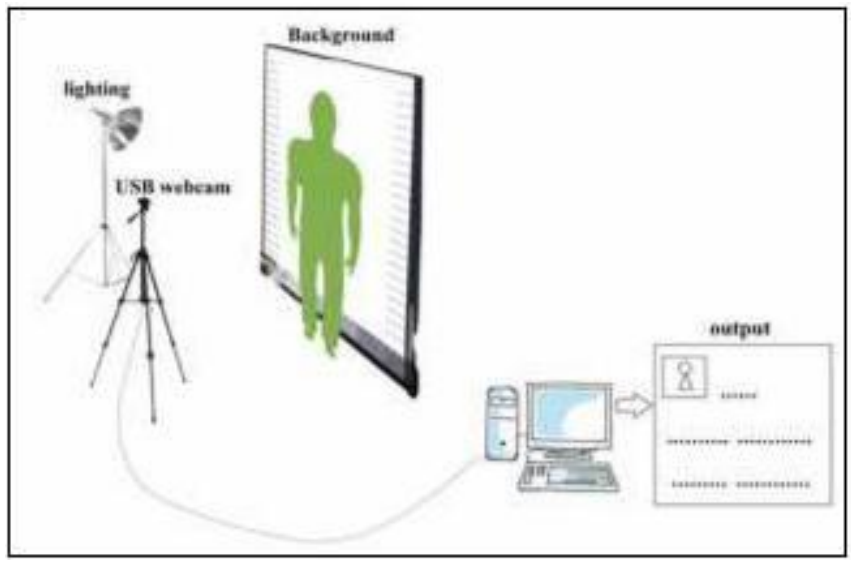

Figure 4. Digital image processing hardware system

In Figure 4 can be explained that the hardware components used are USB Webcam, lighting, background, object and a PC. USB webcam will be connected with a PC that will take an object. Then the next step is to determine the position of the height, angle, and distance of the camera towards the object.

Height of the camera will be organized before the processing is done. Camera height will be adjusted with a distance of the camera object. In addition to the high camera, camera angle is also set in the process of taking pictures of the object. This setting is done so that the object being drawn can meet the frame image on the program which will read high object from the toe to the tip of the head. The function of lighting is to provide lighting objects and help to eliminate noise shadow objects that will cause an error in the program. Shadow noise object will affect the number of pixels that are unreadable on the program and the height measurement becomes less accurate. Lighting used in this research was quite large powerless (100 Watts). So the object fetched will be clearly visible.

For the creation of background photos, use a cloth with a height of 2 metres and a width of 3 meters. The height of the background is set in accordance with the maximum height of a human that is 2 meters, and the width of the background settings specified 3 meters to facilitate the reading of the program in the detection of edge. So that retrieval of objects get perfect results and clean remove objects or other background that could cause an error in the reading program.

After all the hardware is set up, the process of taking pictures of objects do. An image object that has taken the camera will be processed on a computer using a program that has been created, and the image of the object will be processed with image processing techniques to get the height of the object.

\section{Results and Analysis}

In the testing object that is used is a life-sized wooden $200 \mathrm{~cm}, 150 \mathrm{~cm}, 100 \mathrm{~cm}$, and $50 \mathrm{~cm}$. Each variable measured by the object the camera height, distance, and camera angles. At the time of the experiment, the factors that affect the accuracy of a position is laying on wood. When a position leaning wood and not perpendicular then the accuracy of the measurement results are not appropriate or reduced.

High test object is focused on the high camera and distance used. Each object has a height of the camera varies depending on the height of the object. The results of the highest accuracy is approximately $432 \mathrm{~cm}$ to the level of accuracy of $99.5 \%$ and the farther the distance used the value of accuracy will be increasingly reduced as shown in Figure 5 to the height of the camera is $100 \mathrm{~cm}$ and a height of $100 \mathrm{~cm}$ object.

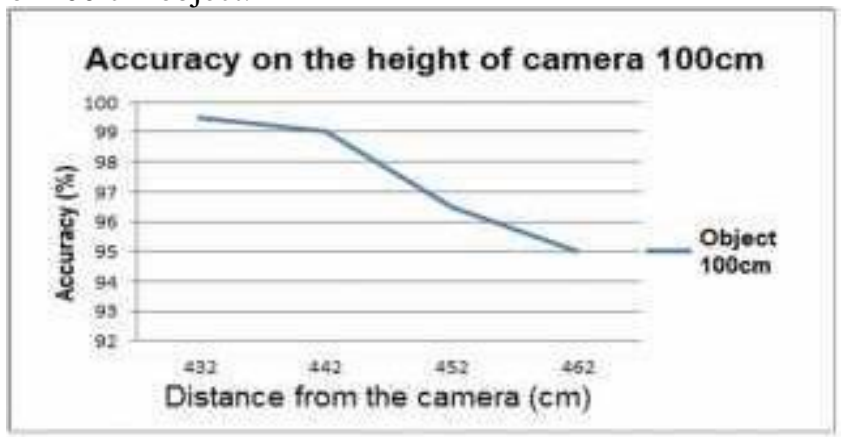

Figure 5. High accuracy graph display camera $100 \mathrm{~cm}$, height object $100 \mathrm{~cm}$.

Figure 6 with a height of $75 \mathrm{~cm}$ and a height of camera object $150 \mathrm{~cm}$, shows the accuracy reaches $100 \%$ at a distance of $432 \mathrm{~cm}$.

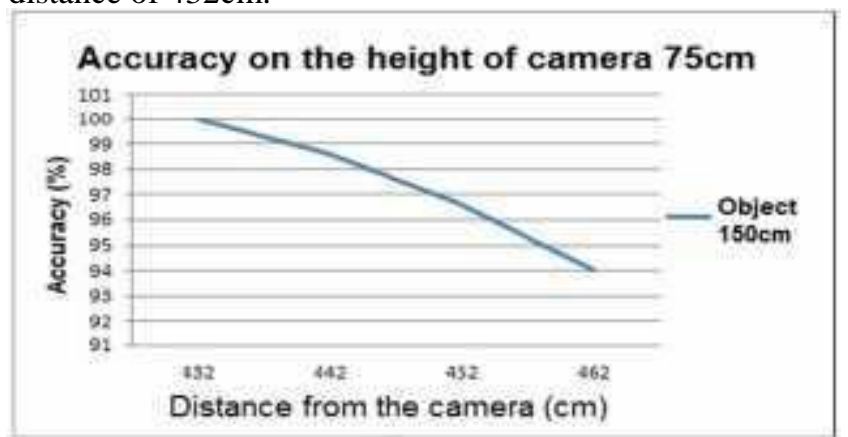

Figure 6. High accuracy graph display camera $75 \mathrm{~cm}$, height object $150 \mathrm{~cm}$.

Achieve $100 \%$ accuracy at a distance $432 \mathrm{~cm}$ can also be seen in Figure 7 with a height of $25 \mathrm{~cm}$ camera and object $50 \mathrm{~cm}$ high. 


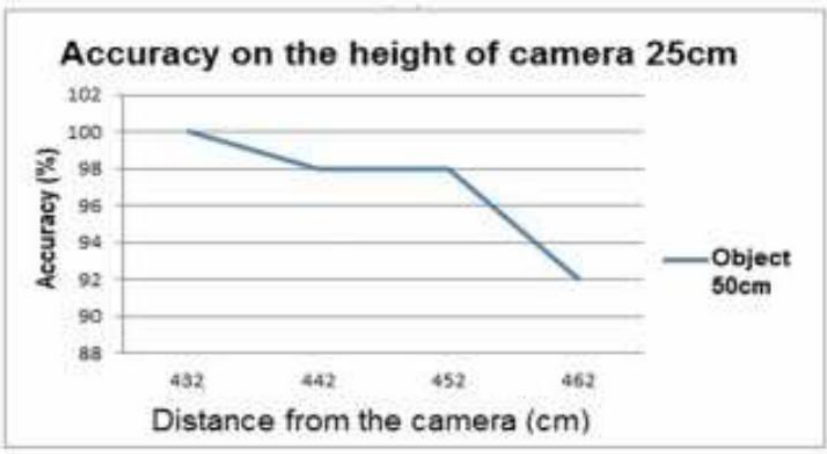

Figure 7. High accuracy graph display camera $25 \mathrm{~cm}$, height object $50 \mathrm{~cm}$.

Testing for the camera angle is done with varying degrees of value on the camera starts from the point perpendicular 900 up to the corner at the time of the object before it is cut off the top and bottom.

The high accuracy of the measured object that will be close to the actual object reference height is at an angle $\geq$ 900. Because when the angle of the camera lens is perpendicular to the object and when the camera angle on the top corner of the 900 , objects that are caught by the camera occupies an ideal shooting position is when the foot of the object approaches the $\mathrm{x}$ axis which can simplify the process of reading and computations in the program.

During the experiment the new parameters are obtained which can affect height measurement by image processing technique, that is the color of the shirt and hijab for women. Testing based on the color of the shirt is testing the image color will be converted into a binary image. In this testing proved that the color of clothes worn when shooting does not affect the readings and calculations on the program.

While the factors that cause errors in readings and calculations are colour hijab for women such as in Figure 8.

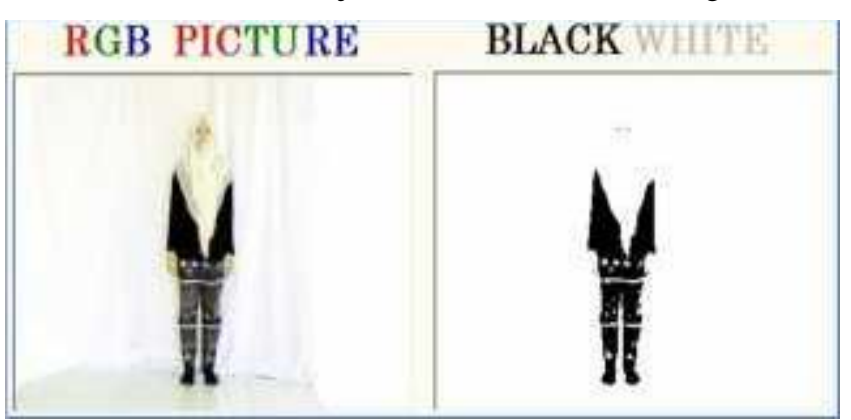

Figure 8. Image conversion.

The colours used can affect the hijab, because at the moment the colour veil color used is similar or the same as the background color such as white, yellow, purple and bright colors will not be read at the time the image is converted on the image binary.

Of the overall experiment, measurement of human height is a major experiment. The result of the binary image processing systems will be analyzed in the scanning process that reads pixels 0 or black -colored object to produce a decision. A number of pixels in the form of data read from the scanning process and the results of these pixels can be expressed as the height has been measured through digital image processing.

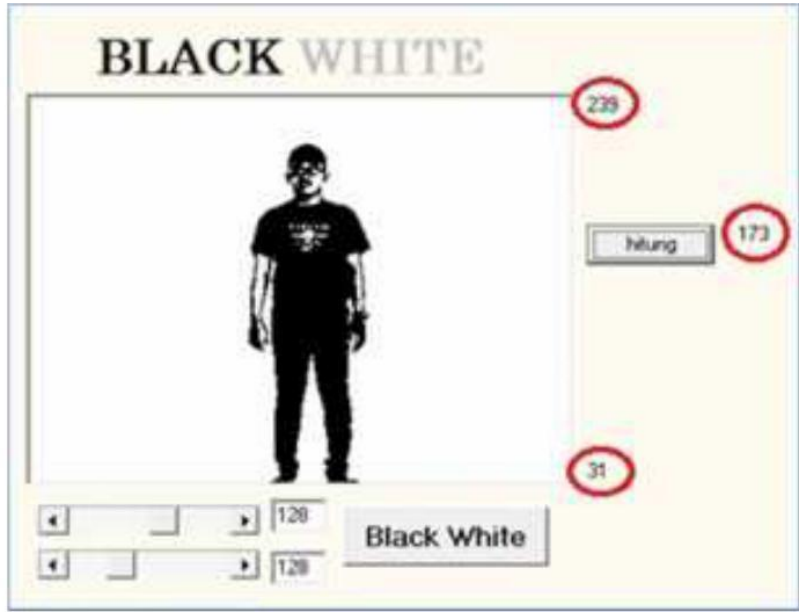

Figure 9. Height measurement results using Delphi.

Reading the pixels from the image can be seen in Figure 9. 239 is pixels maximum and minimum pixel is 31 .

$$
L_{x}=\frac{P_{x}}{P_{r}} \times b_{r}=\frac{(239-31)}{240} \times 200=173 \mathrm{~cm}
$$

Then from the results of the pixels included in the reduction Equation (2) and generate the height that is $173 \mathrm{~cm}$.

\section{Conclusion}

Analysis and discussion of the results it can be concluded that the height measurement system based on digital image processing techniques have been successfully built and can replace the height measurement system manually. For the most accurate object is on a high camera half the height of the object, the camera angle and distance, 900 camera with object is $432 \mathrm{~cm}$. Wearing the same shirt color with the background that is white or a color which is almost similar with white can still be done the process of calculation and reading of the image. While the ideal positions for height measurement using digital image processing techniques is a position or facing the camera turned away from the background. Of the overall testing with high distance changes the camera, the camera, and the camera angle can affect the calculation of the height of an object. The position of an object, the color of the scarf, the colors of the shoe can also affect the calculation of the height of the object, except for the wearing of the color of the shirt.

\section{References}

[1] Akbar RS. Pengukur Tinggi Badan Berbasis Arduino. Jurnal Ilmiah Mikrotek. 2015; 1.4

[2] Debevec PE, Malik J. Recovering high dynamic range radiance maps from photographs. SIGGRAPH International Conference on Computer Graphics and Interactive Techniques. New York. 2008; 31.

[3] Yue ZQ, Chen S, Tham LG. Finite Element Modeling of Geomaterials Using Digital Image Processing. Elsevier Computers and Geotechnics, 2003; 30(5): 375-397.

[4] Shrivakshan GT, Chandrasekar C. A Comparison of various Edge Detection Techniques used in Image Processing. IJCSI International Journal of Computer Science Issues, 2012; 9(5): 1.

[5] Dahab DA, Ghoniemy SS, Selim GM. Automated Brain Tumor Detection and Identification Using Image Processing and 
Probabilistic Neural Network Techniques. International Journal of Image Processing and Visual Communication, 2012; 1(2).

[6] Kirchner M, Fridrich J. On Detection of Median Filtering in Digital images. SPIE Electronic Imaging, 2010; 7541.

[7] Dibya JB. Importance of Image Enhancement Techniques in Color Image Segmentation: A Comprehensive and Comparative Study. Indian J.Sci.Res. 2017; 15 (1): 115-131.

[8] Zhang L, Zhang, L, Mou X, Zhang D. FSIM: A feature similarity index for image quality assessment. IEEE transactions on Image Processing, 2011; 20(8): 2378-2386.

[9] Zulkhairi Z, Widyasari YDL, Akbar M. Perancangan dan Implementasi Pengukuran Jarak dan Tinggi Objek Berbasis Kamera pada Perangkat Mobile. Journal Teknologi Informasi dan Telematika. 2012; 5.(5.1.8): 63

[10] Chin T, Tsai, Cheng P. Vision-based Distance and Area Measurement System. WSEAS Transactions on Signal Processing. 2008; 4. 36-43.

[11] Drago, F., Myszkowski, K., Annen, T. and Chiba, N. Adaptive Logarithmic Mapping For Displaying High Contrast Scenes. Computer Graphics Forum, 2003; 22. 419-426.

[12] Welsh T, Ashikhmin A, Mueller K. Transferring Color to Greyscale Images. ACM Transactions on Graphics, 2002; 21(3): 277-280.

[13] Gatos B, Pratikakis I, Perantonis SJ. Adaptive Degraded Document Image Binarization. ScienceDirect Pattern Recognition, 2006; 39(3): 317-327.

[14] Gorthi SS, Rastogi P. Fringe Projection Techniques: Whither we are?. Optics and Lasers in Engiering, 2010; 48(2): 133-140.

[15] Achmad B, Firdausy K. Pengolahan Citra Digital Menggunakan Delphi. Yogyakarta: ANDI. 2013.

[16] Bovik AL. Editors. The Essential Guide to Image Processing. London: Elsevier Inc. 2009.

[17] Sitorus S, Suyanto, Sawaludin, Harahap S, Hutagalung J. Pengolahan Citra Digital. Medan: USU. 2006. 